IECEC 200220055

\title{
ADVANCED FLYWHEEL TECHNOLOGY FOR SPACE APPLICATIONS
}

\author{
Richard C. Thompson, Joseph H. Beno, and Tony T. Pak \\ Center for Electromechanics \\ The University of Texas At Austin \\ Austin, TX 78712 \\ Phone (512) 471-4496, fax (512) 471-0781 \\ email: r.Thompson, j.beno, or t.pak @mail.utexas.edu
}

\begin{abstract}
For spacecraft applications, energy storage sources are required to produce a high yield with minimum size and mass. Flywheel systems have the potential to fill this need while also providing attitude control for the guidance of the craft. Other advantages include on-board peak power management, extended service life (as compared to chemical batteries), and provisions for redundant systems with minimum effect on the projected payload of the craft.

This paper reviews the results of flywheel design projects carried out at The University of Texas at Austin Center for Electromechanics (UT-CEM), discusses the role of composites in design development, and presents a detailed discussion of a flywheel design currently under study.
\end{abstract}

\section{INTRODUCTION}

Flywheel systems are being designed for use in spacecraft because they offer significant advantages over chemical-based energy sources:

- energy and power systems that provide higher yields can be designed with reduced mass and volume

- the predicted service life of flywheel systems (15+ years) is significantly longer than that expected for the chemical batteries currently used in space applications

- while both chemical and flywheel systems operate within thermal limitations, the temperature range for flywheels is wider

An advanced flywheel design, under development through NRA funding from NASA Glenn Research Center, consists of an arbor that provides a physical connection between a high-strength composite rim and a driven shaft (Fig. 1). Other flywheel designs feature a metallic arbor structure connected to a flywheel rim or a preloaded flywheel design consisting of multiple composite rings press-fit onto a solid metallic shaft. These approaches fall short of the needs of future flywheels with high specific energy because they have these limitations:
- high radial compressive stresses occur in the composite rim, leading to shortened performance life due to creep

- metallic structures are speed limited due to fatigue

- overall; tip speed operation is limited with these designs, and the flywheel rim cannot benefit from use of high-strain composite materials

In developing flywheel designs for space applications, designers at UT-CEM are focused on the arbor design, which has the highest potential for performance improvements. Several major milestones resulted from this development effort: (1) a design for strain-matched composite arbors, and (2) a modeling and analysis tool to assist with design and fabrication of these complex arbors.

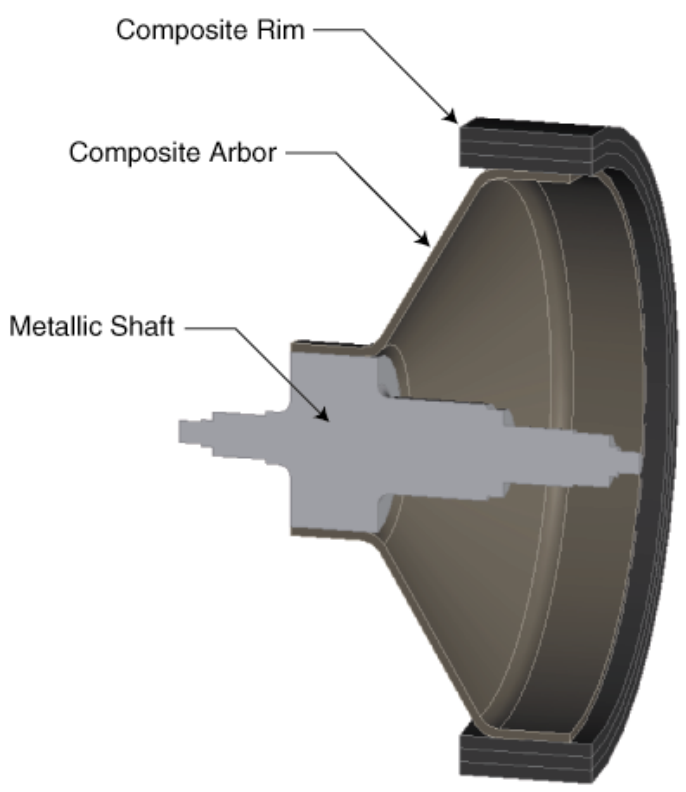

FIG. 1. CONCEPT DESIGN OF AN INTEGRATED FLYWHEEL 
STRAIN-MATCHED COMPOSITE ARBOR DESIGN

A preloaded flywheel design (pictured in Fig. 2) is assembled from multiple individual rings fabricated from high-strength carbon fiber impregnated with a toughened epoxy. All composite rings are assembled by interference fit which preloads the rings and maintains a radial compressive stress state at operating speed, as shown in Fig. 3. A solid metallic hub or shaft serves as the foundation of the preloaded flywheel design. Preloaded composite flywheels are robust, stable structures, but are limited in both speed and thermal operating range to avoid rim/hub separation, leading to loss of mass balance, from both coefficient of thermal expansion mismatches and creep (Pichot, et al, 1997; Whitney and McCullough, 1990; Shapery , 1974).

Rim/hub separation is referred to within the flywheel community as the growth matching problem: the challenge of connecting the flywheel rim (subject to extremely high strains and radial growth) structurally to the driven shaft or hub (low strains and growth) while maintaining a high degree of structural stiffness for rotor dynamic stability. Metallic growthmatching arbors have been implemented successfully, but they are subject to fatigue problems and limit the performance of modern carbon fiber based flywheels. The driving factor in design of a strain-matched arbor, using composite materials, is relief from these limitations.

A past trade study assessed benefits of various technology development opportunities for advanced space flywheel systems in an energy storage role. Partners in this effort were the NASA Glenn Research Center and TRW. Parametric studies were completed that included design-based sizing relations for the primary flywheel components (flywheel, motorgenerator, magnetic bearings, etc.). Actual flywheel layout designs were completed as 3D solid models to verify system mass and ensure realistic packaging. The power and energy levels considered were typical for smaller satellites that use multiple flywheels to (1) accomplish attitude control, (2) provide on-board energy storage to eliminate chemical batteries, and (3) provide suitable redundancy (i.e., satellite is fully functional even if one flywheel system is nonoperational).

Table 1 (following page) shows the results of the study for a flywheel system with these characteristics:

- provides $1 \mathrm{~kW}$ over its full range of speed

- can deliver $500 \mathrm{~W}$-hr of energy operating down to $\sim 70 \%$ depth of discharge

- operates at a peak speed of 50,000 rpm

The total flywheel mass (excluding electronics) is segregated into major sub-component areas. Total flywheel unit mass and delivered energy and power densities for each design appear in the last three columns.

\section{Configuration A}

Starting Point

The initial design configuration was drawn from an in-development design for an engineering module for use on the International Space Station (ISS EM). The ISS EM flywheel uses traditional approaches to stator structures and vacuum housing and conventional stator materials (primarily aluminum). It consists of a solid cylindrical composite energy storage unit made up of concentric rings press-fit (preloaded) together and operates with a rotor tip speed of $\sim 835 \mathrm{~m} / \mathrm{s}$.

\section{Configuration B \\ Reducing Mass}

Advanced light-weight stator structures maximize use of composite materials and incorporate a vacuum housing that is essentially a space frame surrounded by a suitable material. These improvements reduce overall flywheel mass by $3.5 \mathrm{~kg}$.

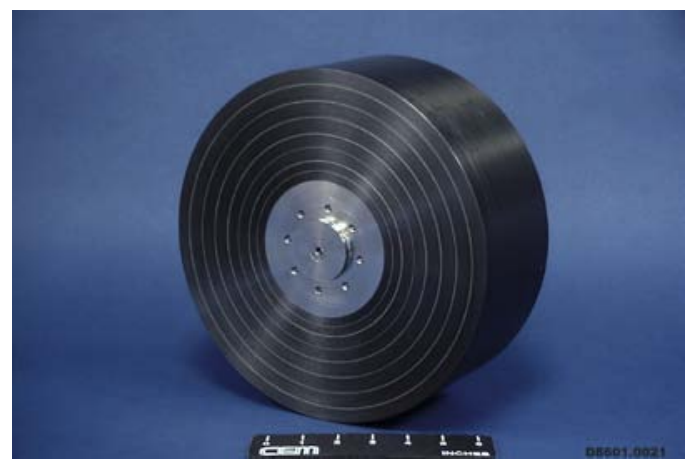

FIG. 2. PRELOADED FLYWHEEL FOR INTERNATIONAL SPACE STATION (ISS)

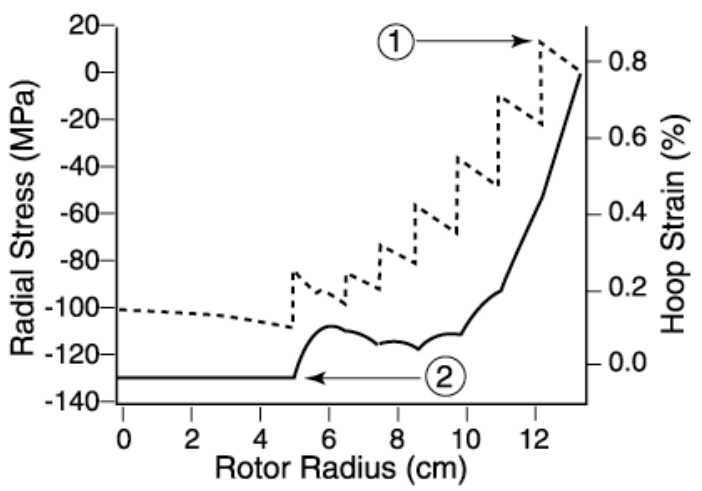

(1) Maximum hoop strain of $0.85 \%$ at $835 \mathrm{~m} / \mathrm{s}$

(2) Maximum radial compressive stress of $131 \mathrm{MPa}(19.1 \mathrm{ksi})$

8601.0040

FIG. 3. PLOT OF ISS PRELOADED FLYWHEEL DESIGN 
TABLE 1. DESIGN CONFIGURATIONS

\begin{tabular}{|c|c|c|c|c|c|c|c|c|}
\hline \multirow[b]{2}{*}{ 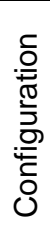 } & \multicolumn{6}{|c|}{ MASS $(\mathrm{kg})$} & \multicolumn{2}{|l|}{ ENERGY } \\
\hline & $\begin{array}{c}\text { Energy } \\
\text { Storage } \\
\text { Rim }\end{array}$ & $\begin{array}{l}\text { Stator } \\
\text { and } \\
\text { Support }\end{array}$ & $\begin{array}{l}\text { Mot-Gen } \\
\text { Stator and } \\
\text { Rotor }\end{array}$ & $\begin{array}{c}\text { Mag } \\
\text { Bearing }\end{array}$ & $\begin{array}{c}\text { Shaft and } \\
\text { composite } \\
\text { arbor } \\
\text { (if used) }\end{array}$ & $\begin{array}{c}\text { Flywheel } \\
\text { Unit }\end{array}$ & $\begin{array}{l}\text { Flywheel } \\
\text { Unit } \\
\text { Delivered } \\
\text { Energy } \\
(\mathrm{W} / \mathrm{kg})\end{array}$ & $\begin{array}{c}\text { Flywheel } \\
\text { Unit } \\
\text { Delivered } \\
\text { Energy } \\
\text { (W-hr/kg) }\end{array}$ \\
\hline A & 12.6 & 6.1 & 1.3 & 2.2 & 0.21 & 22.3 & 45 & 22 \\
\hline B & 12.6 & 2.5 & 1.3 & 2.2 & 0.21 & 18.8 & 53 & 27 \\
\hline C & 10.2 & 2.8 & 1.3 & 1.8 & 0.14 & 16.2 & 62 & 31 \\
\hline D & 4.4 & 3.8 & 1.3 & 1.1 & 2.33 & 13.0 & 77 & 38 \\
\hline
\end{tabular}

\section{Configuration A Starting Point}

The initial design configuration was drawn from an in-development design for an engineering module for use on the International Space Station (ISS EM). The ISS EM flywheel uses traditional approaches to stator structures and vacuum housing and conventional stator materials (primarily aluminum). It consists of a solid cylindrical composite energy storage unit made up of concentric rings press-fit (preloaded) together and operates with a rotor tip speed of $\sim 835 \mathrm{~m} / \mathrm{s}$.

\section{Configuration B \\ Reducing Mass}

Advanced light-weight stator structures maximize use of composite materials and incorporate a vacuum housing that is essentially a space frame surrounded by a suitable material. These improvements reduce overall flywheel mass by $3.5 \mathrm{~kg}$.

\section{Configuration $\mathrm{C}$}

\section{Using Improved Fiber}

UT-CEM has developed a high-strain composite laminate using Toray's T1000G carbon fiber. Using this higher-strength material for the most highly stressed flywheel rings allows the tip speed to increase to $1,150 \mathrm{~m} / \mathrm{s}$. This high-strength composite laminate technology for flywheel applications is currently under development at UT-CEM. The result is a $14 \%$ decrease in mass over configuration $B$.

\section{Configuration D}

\section{Designing a Strain-Matching Arbor}

A strain-matching arbor expands radially with speed to match the radial growth of flywheel rings. Using a composite arbor reduces the total amount of composite material in the rotor, as compared to a preloaded flywheel design of comparable energy storage. When the flywheel design incorporates the high-strength rim material and a composite arbor, the results are:
- maximum rotor speed is increases to $1,150 \mathrm{~m} / \mathrm{s}$

- flywheel unit mass is reduced by $20 \%$ from configuration $\mathrm{C}$

- stored kinetic energy is relatively unchanged, but specific energy has significantly increased

\section{DESIGN ADVANTAGES}

The combined benefits of all improvements are a $42 \%$ decrease in flywheel unit mass, $-75 \%$ increase in specific energy and power of the flywheel unit. The final design, which has significantly reduced the radial compressive stresses in the flywheel rim, avoids the creep problem with preloaded designs, enabling a longer service life, and permits much greater thermal excursions while in normal operation.

The advantages of a strain matched arbor flywheel over a preloaded flywheel, for reduction of radial compressive stresses and wider operating temperatures, are best illustrated in a high performance design comparison. As seen in the table below, parameters for the ISS EM rotor design are shown, highlighting the peak radial compressive stress of $131 \mathrm{MPa}(19.0 \mathrm{ksi})$. This compressive stress state, using a creep-resistant epoxy matrix, is at the edge of acceptable limits for long service life (15 years) at elevated temperature. The preloaded flywheel, with a coupled speed/temperature limitation due to rim-hub thermal growth mismatches, results in a narrow thermal operating range of 21 to $82{ }^{\circ} \mathrm{C}$

Shown in Table 2 are parameters for the advanced flywheel design incorporating the composite arbor. As discussed earlier, this advanced flywheel design, uses UT-CEM's high-strength composite laminate (Toray's T1000G carbon fiber) and operates at a maximum tip speed of $1,150 \mathrm{~m} / \mathrm{s}$. The advanced flywheel design greatly reduces the radial compressive stress in the flywheel rim, to an acceptable level of about $51 \mathrm{MPa}(7 \mathrm{ksi})$; also 
permitting an advantageous operating temperature range of $-46^{\circ} \mathrm{C}$ to $121^{\circ} \mathrm{C}$ and projected longer service life.

\section{MODELING AND ANALYSIS TOOL: CEMWIND}

Composite arbors are complex filament-wound structures that are challenging to design, analyze and fabricate (Soanes, 1988; Menges, Wodicka, and Barking, 1978; Li, 1987). Under a research grant from the State of Texas, UT-CEM developed a new modeling technique for the design, finite element analysis (FEA), and fabrication of advanced filamentwound structures such as composite arbors.

This software package (CEMWIND) constructs an analytical model that generates an axisymmetric mathematical (i.e., computerized) description of the filament wound arbor, as would result from the lay down of fiber tow onto a mandrel. Because of the intricacies of filament winding (changing tow angles), the mathematical model serves to:

- evaluate associated fabrication parameters for the arbor, including bridging and tow slippage

- develop a database of material and geometry properties, as a function of the mandrel axis and through the radial thickness of the arbor to fully account for the orthotropic material properties of the individual layers making up the structure

- generate a detailed FEA structural model directly from the material property and geometry database which then outputs resolved stress and strain responses along a coordinate system aligned with the fiber tow path

\section{CONCLUSION}

UT-CEM is participating in the design of a high specific energy, integrated arbor-and-rim flywheel. It is anticipated that by constructing the arbor and rim with a high-strain composite laminate, it will be possible to design flywheel systems that deliver higher energy and power with reduced weight and volume. These systems may be integrated into spacecraft guidance systems to provide increased attitude control, and may increase the viability of long duration space missions by providing a lower cost, longer life alternative to high-maintenance chemical batteries. In support of this design effort, UT-CEM has developed high-strength composite materials and in-house modeling and analytical tool (CEMWIND) for complex filament wound structures.

\section{ACKNOWLEDGMENT}

The advances described in this paper are the result of efforts supported through a number of different projects. The authors acknowledge gratefully the funding contributions of the State of Texas and NASA Glenn Research Center.
TABLE 2. COMPARISON OF PERFORMANCE CHARACTERISTICS

\begin{tabular}{|l|c|c|}
\hline \multicolumn{1}{|c|}{ Parameter } & $\begin{array}{c}\text { Preloaded rotor } \\
\text { design for the } \\
\text { ISS EM system } \\
\text { with IM7 } \\
\text { composites }\end{array}$ & $\begin{array}{c}\text { Advanced rotor } \\
\text { design with } \\
\text { strain-matched } \\
\text { arbor and high- } \\
\text { strength rim } \\
\text { material }\end{array}$ \\
\hline $\begin{array}{l}\text { Tip Speed } \\
\text { (m/s) }\end{array}$ & $835 \mathrm{~m} / \mathrm{s}$ & $1,150 \mathrm{~m} / \mathrm{s}$ \\
\hline $\begin{array}{l}\text { Minimum } \\
\text { Operating } \\
\text { Temperature }\end{array}$ & $\begin{array}{c}21^{\circ} \mathrm{C} \\
\left(70^{\circ} \mathrm{F}\right)\end{array}$ & $\begin{array}{c}-46^{\circ} \mathrm{C} \\
\left(-50^{\circ} \mathrm{F}\right)\end{array}$ \\
\hline $\begin{array}{l}\text { Maximum } \\
\text { Operating } \\
\text { Temperature }\end{array}$ & $\begin{array}{c}82^{\circ} \mathrm{C} \\
\left(180^{\circ} \mathrm{F}\right)\end{array}$ & $\begin{array}{c}121^{\circ} \mathrm{C} \\
\left(250^{\circ} \mathrm{F}\right)\end{array}$ \\
\hline $\begin{array}{l}\text { Maximum } \\
\text { Hoop } \\
\text { Strain }\end{array}$ & $0.85 \%$ & $1.24 \%$ \\
\hline $\begin{array}{l}\text { Maximum } \\
\text { Radial } \\
\text { Compressive } \\
\text { Stress }\end{array}$ & $\begin{array}{l}131 \mathrm{MPa} \\
(19.0 \mathrm{ksi})\end{array}$ & $\begin{array}{l}51 \mathrm{MPa} \\
(7.4 \mathrm{ksi})\end{array}$ \\
\hline
\end{tabular}

\section{REFERENCES}

Li, Xian-Li, 1987, "Kinematic Equations of Filament Winding on a Curved Tube and Winding Pattern Design," Composite Structures 4: Proceedings of the Fourth International Conference, Volume 2, (A8831426 12-24), London and New York, Elsevier Applied Science, 1987, pp 2.395-2.407.

Menges, G., Wodicka, R., and Barking, H.L., 1978, "Non-geodesic Winding on a Surface of Revolution," Proceedings of Reinforced Plastics/Composites Institute 33rd Annual Technical Conference Proceeding, (A79-15526 04-24) New York, Society of the Plastics Industry, Inc., pp 10-D1 to $10-\mathrm{D} 4$.

Pichot, M. A., Kramer, J. M., Hayes, R. J., Thompson, R. C., Beno, J. H., 1997, "The Flywheel Battery Containment Problem," SAE Publication No. 970242, Society of Automotive Engineers.

Schapery, R.A., 1974, "Viscoelastic Behavior and Analysis of Composite Materials," Composite Materials, Vol. 2, Academic Press, pp. 85-168.

Soanes, R., 1988, "Mathematical Aspects of the Off-line Programming of Filament Winding Machines for General Surfaces of Revolution," Technical Report ARCCB-TR-88036, U.S. Army Armament Research, Development and Engineering Center, Benet Laboratories, Watervliet, N.Y.

Whitney, J. M. and McCullough, R. L., 1990, "Introduction to Viscoelasticity" in "Micromechanical Materials Modeling," Delaware Composite Design Encyclopedia, v2, section 2.5, Technomic Publishing Co. 